\title{
Tropiske orkaner - påvirkning af fremtidens geologi
}

Af Gunver Krarup Petersen, Geologisk Institut, Københavns Universitet.

Den tropiske orkan Katrina blev mest kendt for sine ødelæggelser af flere byer ikke mindst New Orleans - og naturligvis for de over 1.200 omkomne, den var skyld i. Men hvad sker der rent geologisk - kan en voldsom orkan iagttages i en lagsøjle i eftertiden?

Det er en af geologiens grundsætninger, at “nutiden er nøglen til fortiden”. Disse ord udløser ofte en forventning om, at det er de typiske vejrsituationer/bølgestørrelser/vandføringer og så videre, som udformer et givet områdes aflejringer.

Derfor er det naturligt at spørge i hvor høj grad årets vilde sæson for tropiske orkaner i Atlanten (hurricanes) er noget, der udformer aflejringer og erosionsflader, som $\mathrm{i}$ fremtiden vil kunne iagttages i den geologiske lagsøjle.

Således efterlod Hurricane Katrina dramatiske ændringer i fordelingen af land og hav, samt i kystliniens udformning, at det var tydeligt, at den på få døgn ændrede mange forudgående års aflejringer og resulterende morfologi.

Effekt af en passage af en tropisk orkan Som beskrevet af Niels Hansen og John Cappelen andetsteds i dette nummer er en tropisk orkan et lavtryk med høj vindhastighed og store nedbørsmængder. Alle disse tre karakteristika spiller en rolle for orkanens påvirkning af de kystområder, den passerer.

Under et lavtryk kan havspejlet stå lidt højere end i områder med normalt tryk eller højtryk. Væsentligere er det, at der foran orkanen sker en opstuvning af vand (storm surge). Tilsammen giver lavtryk og vindstuvning dermed højere vandstand $i$ kystområderne med fare for oversvømmelser og digebrud. Dette forstærkes naturligvis af bølgerne, som under orkanen vokser dramatisk i størrelse Under orkanen Katrina steg vandstanden ca. $10 \mathrm{~m}$ i visse områder, og dette resulterede selvfølgelig $i$, at store dele af den lavtliggende deltaslette blev oversvømmet. I begyndelsen af november har US Geological Survey opmålt, hvor store landområder der forsvandt i forbindelse med orkanerne Katrina og Rita. De samlede

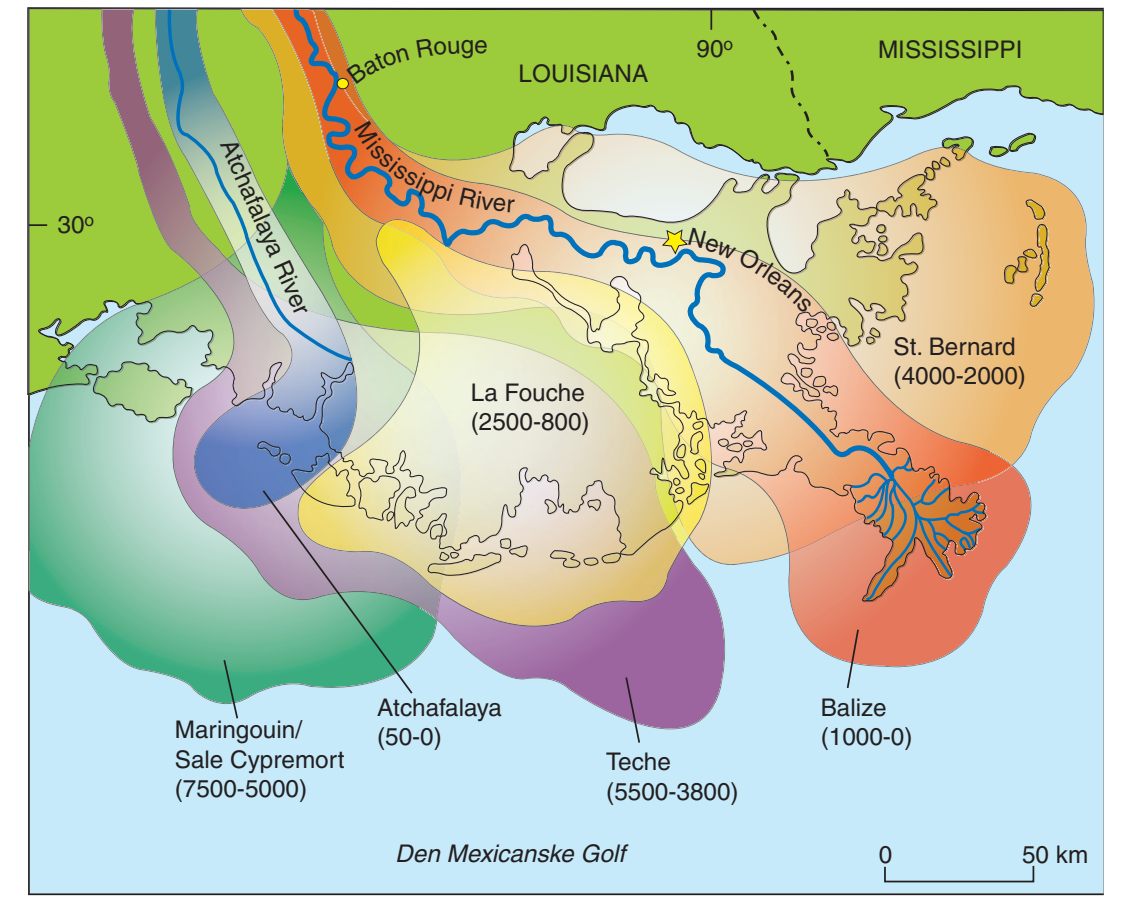

Billedet viser, at den nuværende deltaslette er opbygget af Mississippis forskellige løb gennem de seneste ca. 7.000 år. I det tidsrum har flodens løb skiftet position flere gange. I et naturligt system vil der ske en opbygning af deltasletten i de områder, der ligger ncer floden, hvorimod summen af indsynkning og langsom sedimentation vil føre til, at der sker en transgression i de områder, der ligger langt fra floden. (Grafik: UVH modificeret efter Skinner \& Porter, 2000)

arealer opgøres til 100 kvadratmil af det sydøstlige Louisianas marskområder. Det er endnu for tidligt at bedømme, hvor stor en del af disse områder der vil re-etableres, men US Geological Survey forventer, at en del af områderne vil være permanent omdannet fra sumpe til åbne søer (pressemeddelelse fra Reuter).

Den højere vandstand og de meget større bølger betyder at der under orkanen også sker en erosion i strandplanet (shoreface).

Kystlinien udsættes derfor for stærk erosion, men der sker også aflejring landværts i form af overskylsvifter (wash-over fans) og havværts i form af stormsandslag.

Den nedbør, som falder under den tropiske orkan, giver et ekstra bidrag til oversvømmelserne af lavtliggende områder og er med til at øge belastningen af levèer (naturlige floddiger opbygget af fint sediment, når floden går over sine bredder) og menneskeskabte diger langs floder og søer.

\section{Overskylsvifter}

Overskylsvifter er velbeskrevet fra kyster med barriere-øer. Sand skylles ind på eller over barrieren og aflejres i den bagved- liggende lagune, som et centimeter-tykt lag. Staten Louisianas sydlige kystlinie defineres over en strækning af Chandeleur Islands. Denne række af øer mindskedes dramatisk i størrelse under orkanen Katrina, som det ses af billederne optaget af US Geological Survey før og efter orkanen.

\section{Stormsandslag}

Stormsandslag er beskrevet og tolket fra mange geologiske lagserier. Det er sandlag, som typisk er 1-20 centimeter tykke med erosiv bund, graderet lagdeling og en række sedimentære strukturer, hvor i blandt hvælvet skrålejring (hummocky cross stratification) ofte ses.

Fra den Mexicanske Gulf er der i bore- 


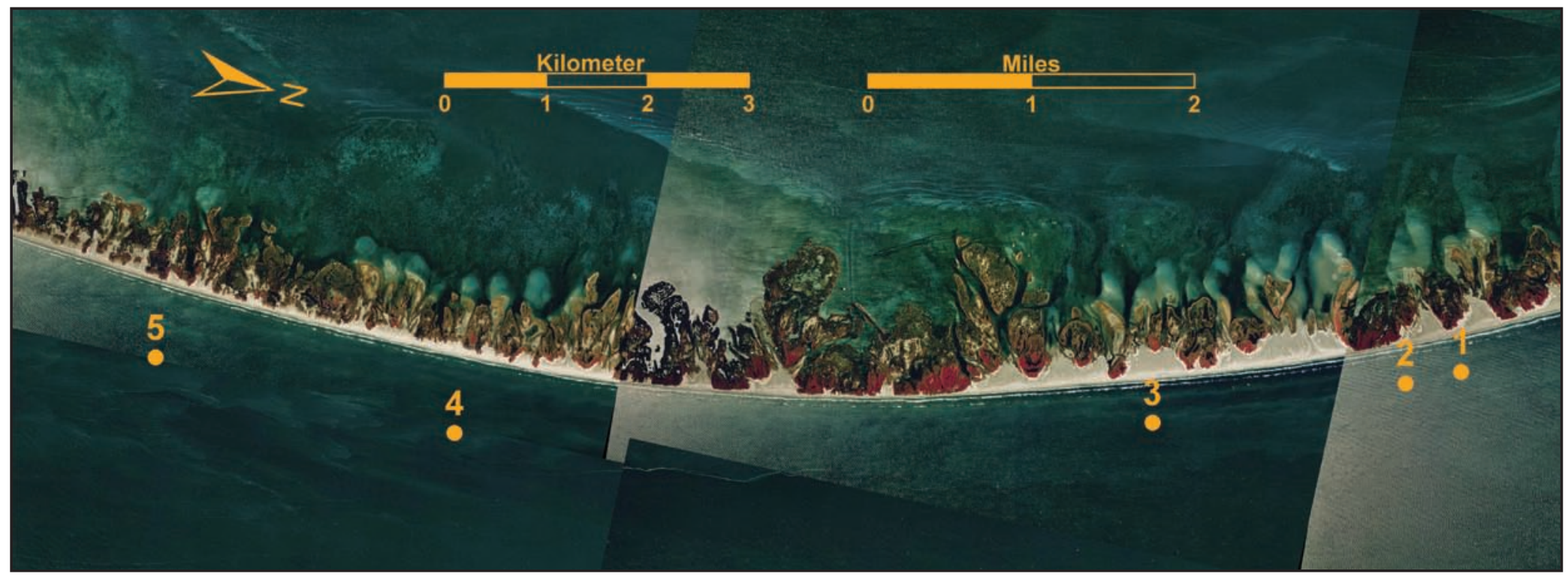

kerner beskrevet recente stormsandslag fra tidligere passager at tropiske orkaner. US Geological Survey har publiceret adskillige fotografier af de kystområder, som lå under øjet i orkanen Katrina. Sammenligninger af billeder før og efter orkanen viser, at der "mangler" sand langs mange kyststrækninger. Det er sandsynligt, at en del af dette er transporteret havværts og aflejret på dybere vand som et stormsandslag.

\section{Deltaer}

Deltaer dannes ved en flods udløb i havet (eller i en sø), og de udgør ofte depocentre dvs. områder, hvor det indenfor et givet tidsrum er aflejret en tykkere sedimentlagserie end i sammenlignelige områder. Et delta omfatter to overordnede aflejringsmiljøer: deltafronten og deltasletten.

Deltafronten (delta front) er den del af deltaet, som strækker sig fra kystlinien til bassinbunden. Her sker sedimentationen altså under havoverfladen, og deltafronten karakteriseres af de samme processer som andre marine kyststrækninger, eksempelvis stormsandslag. I geologiske lagserier fremtræder deltafrontens aflejringer ofte som en succession, hvor sedimentets gennemsnitskornstørrelse stiger opad, og hvor de sedimentære strukturer er dannet under stigende energi, en såkaldtopad-grovende succession.

Deltasletten (delta plain) er den del af deltaet, som ligger inden for kystlinien. Deltasletten er typisk flad og lavtliggende med store vådområder. Deltasletten omgiver flodens nedre løb og omfatter deltafordelingskanaler (distributary channels), sumpe, søer, marskområder og deltabugter (interdistributary bays). Omkring deltakanalerne kan der opbygges naturlige floddiger (levèer), og disse er i nogle tilfælde forstærket af opførte diger. Konsekvensen heraf kan blive, at vandstanden i floden er betydeligt over deltasletten. Digebrud vil føre til aflejring af sandlag (crevasse splays) hen over de tørve- og mudderlag, som karakteriserer dele af deltasletten.

\section{Mississippideltaet}

Hele Mississippideltaet undergår en tektonisk indsynkning i nutiden i størrelsesorde-

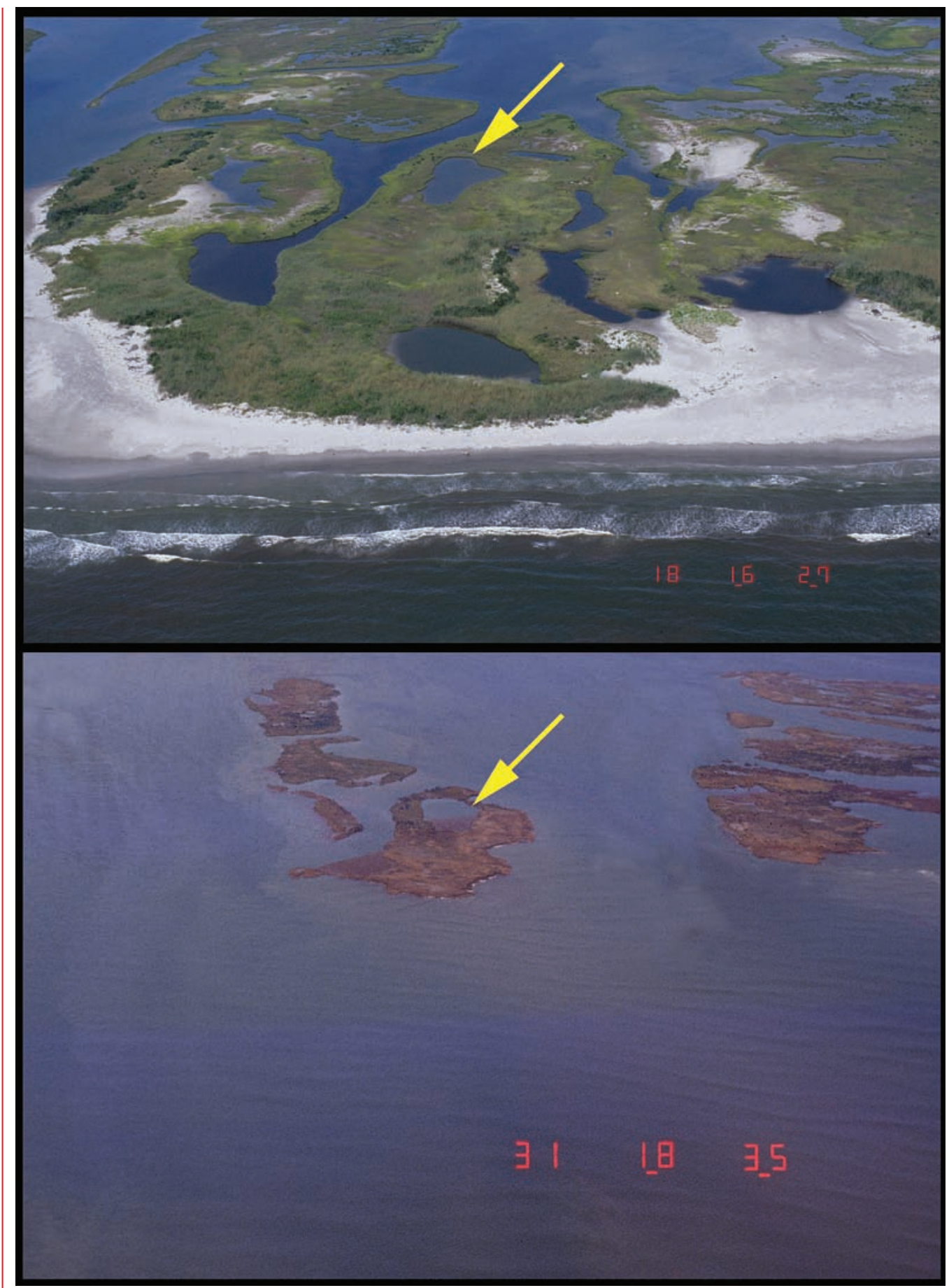

Billedet øverst er et oversigtsbillede fra Chandeleur Islands. Øerne er små, lavtliggende og overvejende dcekket af lav vegetation. De hvide områder består af sand, som er aflejret i overskylsvifter. De to detailbilleder er fra lokalitet 1 og viser forandringen fra før Katrina til efter. Det ses, at øens areal efter orkanen er meget lille. (Fotos er venligst udlånt af U.S. Geological Survey) 
nen $10 \mathrm{~mm} / \mathrm{a} r$, om end dette tal varierer fra mindre end $5 \mathrm{~mm}$ til mere end $15 \mathrm{~mm} / \mathrm{a} r$. Konsekvensen heraf er, at de dele af deltasletten, som ikke modtager sediment fra floden, eller hvor der ikke dannes tørv, langsomt vil komme til at ligge under havniveau.

Mississippideltaets deltaslette har undergået store ændringer gennem de sidste ca. 7.000 år, idet Mississippi har forlagt sit løb mindst 5 gange. Ved udmundingen af floden og deltakanalerne sker der en udbygning (progradering) af kystlinien, og flodløbet forlænges derved, samtidig med at faldet bliver mindre. Efter ca. 1.000 års forløb definerer floden et nyt løb, og den forladte del af deltasletten domineres af indsynkning. Efterhånden omdannes ferskvandssumpene til marskområder, og til slut sker der en marin transgression.

Efter yderligere indsynkning skabes "plads" til en ny fase af progradering. Denne udvikling er veldokumenteret $\mathrm{i}$ Mississippideltaet (illustreret i de fleste geologiskelærebøger).

Nogle af de samfundsmæssige og politiske problemer, som blev tydelige under Katrina, skyldes menneskets indgriben og forsøg på at kontrollere et komplekst sæt af naturlige processer. Tidsskriftet "National Geographic" bragte i oktober 2004 en skrækhistorie om en fremtidig oversvømmelse af New Orleans. Historien var dog bygget på så grundig research, at den blev uhyggeligt aktuel under Katrina.

Deltaslettens respons på tropisk orkan I sin naturlige tilstand vil Mississippi gå over sine bredder (overbank flooding) og herved aflejre sediment på deltasletten. Dette vil endvidere tilføre sumpområderne næringsstoffer, som stimulerer plantevæksten og modvirke effekten af den tektoniske indsynkning. For befolkningen langs Mississippi har de tilbagevendende oversvømmelser været en risiko, og siden 1920-erne har man forsøgt at hindre dem gennem omfattende digebyggeri. Konsekvensen er, at deltasletten herved "udsultes" for sediment. Omkring New Orleans har man forhøjet og forstærket digerne med den virkning, at store dele af byen nu ligger i bunden af en "skål" og er udsat for oversvømmelser fra såvel Mississippi som Lake Ponchartrain.

Deltasletten i det sydlige Louisiana gennemskæres af et antal kanaler, som er anlagt til brug for skibsfarten og olieindustrien. I forbindelse med forhøjet vandstand under en orkanpassage medvirker kanalerne imidlertid til en indtrængen af saltvand ind over sumpområderne. Dette tåler vegetationen ikke, og ferskvandssumpene afløses derfor af marsk, hvor planteproduktionen og tørvedannelsen er mindre. Som resultat heraf sker der en nedbrydning af de vådområder, som i dag danner en beskyttelse for de beboede områder, og på længere sigt fremmes den marine transgression af deltasletten.

Endelig skal det tages i betragtning, at det nuværende udløb af Mississippi aflejrer en del sediment på relativt dybt vand, hvorfor den kystparallelle transport af sediment ikke modvejer den erosion, der sker af øerne langs kysten.

Igennem mange år har der fundet et tab af landområder (land loss) sted i det sydlige Louisiana. Menneskets indgriben i det naturlige system betyder, at den mængde sediment, som transporteres i Mississippi, passerer forbi deltasletten og aflejres på dybere vand i Den Mexicanske Golf. Herved forskubbes balancen mellem indsynkning og tilvækst (aggradering) af deltasletten, med det resultat at dele af deltasletten trangrederes.

\section{Langtidsvirkning af en orkan}

Nogle af virkningerne efter orkanen Katrina, vil formodentlig ikke kunne iagttages om nogle år. Andre resultater må formodes at være uoprettelige. Nedbrydningen af barriereøerne kan ikke vendes, og de vil ende som undersøiske sandbanker. I et geologisk perspektiv er dette ikke tragisk, men et aktuelt eksempel på, at lavtliggende kystnære områders udvikling styres af et komplekst samspil mellem sedimenttilførsel, omlejring og indsynkning. 